\title{
THE EFFECTS OF WEATHER ON CRIME RATES IN MALAYSIA
}

\author{
Muzafar Shah Habibullah* \\ Universiti Putra Malaysia
}

\begin{abstract}
This study estimates the effects of temperature and rainfall on the prevalence of criminal activity in Malaysia. The analysis is based on annual data for the period 1973-2009, on temperature, rainfall and crime rates - total crime, violent and property crime. By using the generalized one-step error-correction model, we examine the short-run and long-run dynamics between crime rates with varying temperatures and rainfall in Malaysia. Our results suggest that there is long-run relationship between total crime and property crimes with weather in Malaysia. The long-run coefficients indicate a positive impact of temperature (hot weather) on criminal activity. Our results imply that the law enforcement would have a better understanding of how the weather affects crime and a chance for the authorities to better prepare their departments during weather conditions that influence certain criminal activities.
\end{abstract}

Keywords: Crime; Temperature; Rainfall; Generalized error-correction model; Malaysia.

\section{INTRODUCTION}

Voluminous of literatures have relate the incidences of changing weather or climate change to criminal activities. Climate change can even lead to social conflict that includes interstate conflict, civil war and conflict between smaller groups within states (Agnew, 2011; Anderson, 2012). Agnew (2011) posits that strains such as anger, frustration and fear can be impacted by climate change. In order to reduce or escape from strain people will resort to crime. Anderson (2012) argues that global warming can result an uncomfortably warm temperature that could instigate irritability, aggression and violent behaviour, and thus, risking children to be violence-prone individuals as well as exposing the livelihood and survival of the population to sudden risk. For example, extreme weather such as floods, hurricanes, droughts, wildfires and blackouts which have devastating effects that can lead to physical injury, death, displacement of people, destruction of homes, properties and infrastructures, loss of livelihood, shortages of fresh water and food, occurrences of diseases, disruption of routine activities - all these lead to additional strains. Given a weak government/states and are no longer able to exercise effective social control, angry and hungry people will ultimately resort to violent and crime.

Nevertheless, majority of the weather-crime related studies have been focusing on the role of temperature affecting crime, in particular violent crime. For example, earlier studies by Anderson (1989), Anderson and Anderson (1984), Cohn (1990), and Cotton (1986) show evidence that temperature has a positive effect on violent crime and other types of aggressive behaviour. The heat hypothesis popularized by Anderson (1989) suggests that hot temperatures cause physiological changes, thereby increasing the probability of hostile and aggressive behaviour. Anderson (2001) observes that rates of violent crime increased during the hottest times of the year, and were higher in the regions with

*Corresponding author: Faculty of Economics and Management, Universiti Putra Malaysia, 43400 UPM Serdang, Selangor, Malaysia. Tel: +60389467635 Email: muzafar@upm.edu.my 
hotter climates. On the other hand, rainfall and cold weather reduces crime. This is because, during cold and wet weather, people tend to stay indoors and/or at home.

More recent studies further supported the evidence that weather induces people to commit crime. McLean (2007) found that both the maximum temperature and hours of sunshine had impacted positively on the number of sexual assaults committed in a day in the Greater Manchester, United Kingdom. On the other hand, Tompson and Bowers (2015) found that temperature, wind speed and humidity being a significant predictors of robbery during the night shift and weekends in the Strathclyde region of Scotland; while rain show a negative relationship with robbery at the weekends as people are less likely to venture outdoors when it is raining when travel behaviour is optional. Sorg and Taylor (2011) investigate the impact of temperature on monthly street robbery counts in the U.S. Philadelphia communities using census tract for 2007 - 2009; and their study suggests that community robbery counts were higher when temperatures were higher, in particular in the lower socioeconomic status communities.

For Malaysia, using remote sensing and GIS technology to relate ambient temperature and the highly potential crime rate area in Shah Alam Selangor, Salleh et al., (2012) show that there is correlation between the ambient temperature and the criminal activities. On the other hand, to investigate the effect of weather on crime in New Zealand, Horrocks and Menclova (2011) uses daily data from 43 police districts across the country from 2000 to 2008; and employing a panel econometric techniques, their study suggests that temperature (positive) and rainfall (negative) are found to have a significant effect on the number of violent crimes recorded. Furthermore, Horrocks and Menclova (2011) found that both temperature and rainfall affects the number of property crimes positively. A study on 2997 counties of the United States, Ranson (2014) indicates that temperature has a strong positive effect on criminal behaviour. According to Ranson (2014), their study predicted that between 2010 and 2099, climate change will cause an additional 22,000 murders, 180,000 cases of rape, 1.2 million aggravated assaults, 2.3 million simple assaults, 260,000 robberies, 1.3 million burglaries, 2.2 million cases of larceny, and 580,000 cases of vehicles theft in the United States.

The purpose of the present study is to investigate the impact of temperature and rainfall on the prevalence of criminal activities in Malaysia. The analysis is based on a 37-year (1973-2009) period of annual (average) temperature and (average) rainfall and crime rates - total crime, violent and property crimes. By using the generalized one-step error-correction model, we examine the short-run and longrun dynamics between crime rates with varying temperatures and rainfall in Malaysia.

The paper is organized as follows. In section 2, we review the related theories on crime-weather studies. The method, data and model used in the study are discussed in section 3. In section 4, we present and discuss the empirical results. The last section is our conclusion.

\section{WEATHER-CRIME RELATED THEORIES}

In the crime-weather literature, there are three well known theories linking the effect of weather conditions on criminal activities. The Negative Affect Escape Model (NAAM) proposed by Baron (1972), Baron and Bell (1976), and Bell and Baron (1976) contend that aggressive behaviour increases with increases in temperature because of the increase in the negative affect such as irritation, annoyance and discomfort. However, the increase in aggression as temperature increases only up to a certain level, thereafter, further increase in temperature results in the decrease in aggression because the motivation 
to escape uncomfortable situations outweighs the aggressive motives. This curvilinear, inverted-U shaped relationship between crime and weather has been supported by among others; Andersan and Anderson (1984), Cohn and Rotton (1997), Van de Vliert et al. (1999), Horrocks and Menclova (2011), and Gamble and Hess (2012).

On the other hand, Anderson et al. (1995) put forward the General Affective Aggression Model (GAAM) that postulate higher temperatures facilitate affective aggression. The model predicts that hot temperature produced increases in hostile affect, hostile cognition and physiological arousal. According to Anderson et al. (1995), a person's acute situational variables such as pain, discomfort, and frustration determine a person's arousal (e.g., psychological, perceived), state of affect (e.g., hostility, anger) and cognitions (e.g, hostile thoughts, hostile memories). For example, hot temperature will affect acute situational variables of a person, such as discomfort. Uncomfortable conditions should arouse negative affect (such as hostility or anger), heightens physiological arousal, and primes aggressive thoughts and most likely this will lead to aggressive behaviour such violent acts (Rotton and Cohn, 2003).

The Routine Activity (RA) theory proposed by Cohen and Felson (1979) assert that a criminal event requires three elements: a motivated offender, a suitable target, and the absence of capable guardians. The guardian in this sense is not necessarily the police but includes families, relatives, friends, or neighbours or even bystanders. The suitability of a target is governed by its value, visibility and accessibility to the possible offender, and the perceived net benefits of committing crime. Thus, for a crime to happen a suitable target must be available, a capable guardian is absence, and a motivated offender must be present. Relating this to weather, Cohn (1990) explains that during warm weather, people are more likely to stay away from their homes to public places, resulting in greater opportunities for personal interaction and lead more people being victimized. The increase in the number of empty dwellings will therefore increase the likelihood of burglaries (Cohn and Rotton, 2000; Butke and Sheridan, 2010).

\section{METHODOLOGY}

To examine the long-run as well as the short-run dynamics of the relationship between crime and weather, we employ the popular error-correction model. Banerjee et al. $(1993,1998)$ has criticized the two-stage error-correction models of giving substantial small-sample bias compared to the one-step error-correction model, where the long-run relation is restricted to being homogenous. In this study, following Yasar et al. (2006) the generalized one-step error-correction model (ECM) is estimated.

We define the following autoregressive distributed lag ARDL $(2,2,1,1)$ model:

$$
\begin{aligned}
\text { crime }_{j t}= & \delta_{1} \text { crime }_{j t-1}+\delta_{2} \text { crime }_{j t-2}+\alpha_{0} \text { weather }_{i t}+\alpha_{1} \text { weather }_{i t-1}+ \\
& \alpha_{2} \text { weather }_{i t-2}+\beta_{0} \text { unemployment }_{t}+\beta_{1} \text { unemployment }_{t-1}+\varphi_{0} \text { population }_{t}+ \\
& \varphi_{1} \text { population }_{t-1}+\mu_{i j t}
\end{aligned}
$$

with $\mu_{i j t}$ is the stochastic error, and $i$ is the weather component - temperature or rainfall, $j$ is the crime rates consisting of the total crime, property and violent crime rates, and $t$ is time periods $(t=1, \ldots, T)$; unemployment and population act as the control variables.

Following Banerjee et al. (1993, 1998), equation (1) can be transformed into the following one-step ECM equation that provides an explicit link between the short-run effects and the long-run effects: 


$$
\begin{aligned}
\text { scrime }_{j t}= & \left(\delta_{1}-1\right) \Delta \text { crime }_{j t-1}+\pi\left(\text { crime }_{j t-2}-\text { weather }_{i t-2}\right)+\text { - }_{\text {weather }} \text { we }_{i t} \\
& +\alpha_{0} \Delta \text { weather }_{i t}+\left(\alpha_{0}+\alpha_{1}\right) \Delta \text { weather }_{i t-1}+\beta_{0} \Delta \text { unemployment }_{t} \\
& +\left(\beta_{0}+\beta_{1}\right) \text { unemployment }_{t-1}+\varphi_{0} \Delta \text { population }_{t} \\
& +\left(\varphi_{0}+\varphi_{1}\right) \text { population }_{t-1}+\mu_{i j t}
\end{aligned}
$$

with $\theta=\alpha_{0}+\alpha_{1}+\alpha_{2}+\delta_{1}+\delta_{2}-1$ and $\pi=\delta_{1}+\delta_{2}-1$. Parameter $\pi$, the coefficient of the errorcorrection term, crime $_{j t-2}-$ weather $_{i t-2}$ ) gives the adjustment rate at which the gap between crime and weather is closed. If $\pi$ is negative and significant, then we conclude that the relationship between crime and weather exists in the long-run. The sum of the contemporaneous and the one-period lagged weather capture the short-run dynamics. To calculate the true long-run relationship (elasticity) between crime and weather, we subtract the ratio of the coefficient of the scale effect (two-period lagged value of the weather variable) to the coefficient of the error-correction term, from 1 ; that is, $1-(\hat{\theta} / \hat{\pi})$.

In line with the routine activity theory, it is expected a priori that temperature has positive effect on crime while rainfall, population size and unemployment rate have negative effect on crime. As for the population size, the more number of people at certain area can act as capable guardians, having a controlling effect on the amount of criminal activity. Furthermore, as pointed by Ousey (2000) that in cities and metropolitan areas with higher levels of informal social control would have lower crime rates. On the other hand, unemployment rate can has a positive effect on crime rate. The unemployed are more highly motivated to commit crimes because they are out of work and have financial needs. When unemployment rates are low, more people will spend more time away from home engaging in work or in leisure activities and will be more likely to purchase new consumer goods, resulting in a larger number of more attractive opportunities for crime. On a contrary, a negative relationship between unemployment and crime that is based on routine activities theory hypothesizes that an immediate consequence of unemployment is to reduce crime because the unemployed generally find themselves in routine activities that are more home-based. When unemployment rate is high, the unemployed may be more likely to remain in or near their homes and neighborhoods, thus reduce rate of crime by reducing the overall number of opportunities for criminal acts to occur (Britt, 1997).

In this study, the availability of data on crime rates span from 1973-2009. Data on crime recorded on violent and property crimes (total crime equals violent plus property crimes), population and unemployment rates were collected from various issues of the Malaysia's Statistical Yearbook published by the Department of Statistics Malaysia. All crime rates were measured as per 100,000 populations. Data for temperature and rainfall were collected from various issues of the Monthly Weather Bulletin published by the Malaysian Meteorological Department. In the analysis, all variables were transformed into natural logarithm.

\section{THE EMPIRICAL RESULTS}

Before testing for the long-run relationship (cointegration) between crime and weather using equation (2), we test for the order of integration for all the non-stationary variables. Table 1 shows the result of the unit root test on total crime, violent and property crime rates, unemployment, population, temperature and rainfall, in their levels and first-differences. Clearly, in all cases, the augmented DickeyFuller test (Dickey and Fuller, 1979, 1981) statistics indicate that all seven time-series variables are difference stationary, in other words, they are I(1) in levels. Having noted that all variables are of the same order of integration, we can proceed with the estimation of equation (2) that is the test for cointegration. 
The cointegration tests result is presented in Table 2 . The results in Table 2 suggest that there is a strong long-run relationship between temperature and total crime, property and violent crime rates; while longrun relationships are detected between rainfall and total crime and property crime rates. The statistical significance of the error-correction terms implies that, if there are deviations from long-run equilibrium, short-run adjustment will be made to the dependent variable to re-establish this long-run equilibrium. The result suggests that convergence to equilibrium is quite slow, with a discrepancy of about 30 percent corrected in each period between crime and temperature, and 20 percent between crime and rainfall.

Table 1: Results of Unit Root tests for Total, Property and Violent Crime Rates

\begin{tabular}{ccc}
\hline \hline \multirow{2}{*}{ Series } & \multicolumn{2}{c}{ ADF unit root tests on levels: } \\
\cline { 2 - 3 } & Constant & Constant \& Trend \\
\hline Total crime & $-1.829(1)$ & $-2.410(1)$ \\
Property crime & $-2.005(1)$ & $-2.397(1)$ \\
Violent crime & $-0.703(1)$ & $-2.429(1)$ \\
Unemployment rate & $-1.315(1)$ & $-2.858(3)$ \\
Population & $-2.543(3)$ & $-2.462(0)$ \\
Temperature & $-2.839(3)$ & $-3.433(2)$ \\
Rainfall & $-2.147(0)$ & $-3.436(0)$ \\
\hline & ADF unit root tests on first-differences: \\
\hline Total crime & $-3.947 * *(0)$ & $-3.913 * *(0)$ \\
Property crime & $-3.915 * *(0)$ & $-3.877 * *(0)$ \\
Violent crime & $-4.482^{* *}(0)$ & $-4.417 * *(0)$ \\
Unemployment rate & $-5.065 * *(0)$ & $-4.987 * *(0)$ \\
Population & $-3.362 * *(0)$ & $-5.196 * *(0)$ \\
Temperature & $-8.197 * *(0)$ & $-8.120^{* *}(0)$ \\
Rainfall & $-8.267 * *(0)$ & $-8.135^{* *}(0)$ \\
\hline \hline
\end{tabular}

Notes: Asterisk (**) denote statistically significant at the 5\% level. Critical values are taken from MacKinnon (1996). Figures in parentheses denote lag length chosen by Schwarz criterion. All variables are in natural logarithm.

The magnitude of the short-run (elasticities) effect is measured by the short-run coefficient. From Table 1 , it is evident that the temporary shock from temperature and rainfall impacted positively on all three crime rates; nevertheless, these coefficients are not significant. On the other hand, the long-run elasticities indicate that long-run crime rates response to permanent shocks to the weather conditions is large (model with temperature); a 1 percent increase in temperature increases total crime and property crime rates by 16 percent. However, the long-run elasticities for violent and temperature as well as rainfall and all three crime rates are not significant.

\section{CONCLUSION}

In this study, we investigate the short-run and long-run dynamics of the relationship between the criminal activity in Malaysia and the weather conditions for the period 1973-2009. The long-run relationship between total crime, property and violent crime rates with temperature and rainfall were tested using the generalized one-step error-correction model. Generally, we conclude that the permanent (long-run effect) shocks of the weather condition - temperature induce large positive impact on criminal activity in Malaysia, particularly on the property crime. Our results imply that the law enforcement would have a better understanding of how the weather affects crime and a chance for the authorities to better prepare their departments during weather conditions that influence certain criminal activities in Malaysia. 
Table 2: Estimated Generalized One-Step Error-Correction Model: Long-run and Short-run Responses of Weather on Crime Rates

\begin{tabular}{|c|c|c|c|c|c|c|}
\hline \multirow{2}{*}{ Independent variables } & \multicolumn{3}{|c|}{ Dependent variable, $\Delta$ crime $=f($ temp $):$} & \multicolumn{3}{|c|}{ Dependent variable, $\Delta c r i m e=f$ (rain): } \\
\hline & Total crime & Property & Violent & Total crime & Property & Violent \\
\hline \multirow[t]{2}{*}{ constant } & -12.661 & -12.645 & -11.403 & 1.8148 & 2.0747 & -2.1215 \\
\hline & $(1.9583)$ & $(1.9970)$ & $(1.3931)$ & $(0.7303)$ & $(0.8482)$ & $(0.6440)$ \\
\hline \multirow[t]{2}{*}{$\Delta$ crime $_{j t-1}$} & 0.1119 & 0.1130 & -0.0033 & 0.1512 & 0.1518 & -0.0021 \\
\hline & $(0.7757)$ & $(0.8020)$ & $(0.0185)$ & $(0.9634)$ & $(0.9875)$ & $(0.0114)$ \\
\hline \multirow[t]{2}{*}{ crime $_{j t-2}-$ temp $_{t-2}$} & $-0.2891 * *$ & $-0.2839 * *$ & $-0.3238 * *$ & & & \\
\hline & $(3.2319)$ & $(3.3804)$ & $(2.2455)$ & & & \\
\hline \multirow[t]{2}{*}{ temp $_{t-2}$} & $4.4048 * *$ & $4.4227 * *$ & 3.4969 & & & \\
\hline & $(2.1509)$ & $(2.2034)$ & $(1.3761)$ & & & \\
\hline \multirow{2}{*}{$\Delta$ temp $_{t}$} & 2.0839 & 2.2996 & 0.5400 & & & \\
\hline & $(1.4321)$ & $(1.6156)$ & $(0.2827)$ & & & \\
\hline \multirow[t]{2}{*}{$\Delta t e m p_{t-1}$} & 2.2392 & 2.3497 & 0.5877 & & & \\
\hline & (1.2888) & (1.3848) & $(0.2647)$ & & & \\
\hline \multirow[t]{2}{*}{ crime $_{j t-2}-$ rain $_{t-2}$} & & & & $-0.1841 * *$ & $-0.1808 * *$ & -0.3085 \\
\hline & & & & $(2.2180)$ & $(2.3166)$ & $(2.0406)$ \\
\hline \multirow{2}{*}{$\operatorname{rain}_{t-2}$} & & & & -0.2004 & -0.2552 & 0.4708 \\
\hline & & & & $(0.2916)$ & $(0.3777)$ & $(0.5401)$ \\
\hline \multirow[t]{2}{*}{$\Delta \operatorname{rain}_{t}$} & & & & 0.9996 & 0.9441 & 1.3701 \\
\hline & & & & $(1.8718)$ & $(1.8005)$ & (1.9379) \\
\hline \multirow[t]{2}{*}{$\Delta \operatorname{rain}_{t-1}$} & & & & -0.1627 & -0.2521 & 0.8678 \\
\hline & & & & $(0.2668)$ & $(0.4224)$ & $(1.0675)$ \\
\hline \multirow[t]{2}{*}{ surate $_{t}$} & 0.1697 & 0.1710 & 0.2388 & 0.0924 & 0.0959 & 0.1663 \\
\hline & $(1.4032)$ & $(1.4557)$ & (1.4298) & $(0.6979)$ & $(0.7420)$ & $(0.9349)$ \\
\hline \multirow[t]{2}{*}{ urate $_{t-1}$} & $-0.1557 * *$ & $-0.1679 * *$ & -0.0522 & -0.1236 & -0.1337 & -0.0089 \\
\hline & $(2.0998)$ & $(2.3353)$ & $(0.4583)$ & (1.6888) & $(1.8809)$ & $(0.0797)$ \\
\hline \multirow[t]{2}{*}{$\Delta p o p_{t}$} & $-7.4754 * *$ & $-7.5623 * *$ & -6.4654 & $-7.5087 * *$ & $-7.5540 * *$ & -7.2000 \\
\hline & $(2.2925)$ & $(2.3724)$ & (1.4882) & $(2.2697)$ & $(2.3299)$ & $(1.6407)$ \\
\hline \multirow[t]{2}{*}{ popp $_{t-1}$} & -0.0916 & -0.1291 & 0.2349 & -0.0756 & -0.0992 & 0.2228 \\
\hline & $(0.8657)$ & $(1.3010)$ & $(0.9864)$ & $(0.6512)$ & $(0.9010)$ & $(0.9377)$ \\
\hline \multicolumn{7}{|l|}{ Summation: } \\
\hline \multirow[t]{2}{*}{ Long-run elasticities } & $16.236^{* *}$ & $16.575 * *$ & 11.799 & -0.088 & -0.411 & 2.526 \\
\hline & {$[0.019]$} & {$[0.015]$} & [0.164] & [0.980] & [0.911] & [0.367] \\
\hline \multirow[t]{2}{*}{ Short-run elasticities } & 4.323 & 4.649 & 1.127 & 0.836 & 0.691 & 2.238 \\
\hline & [0.126] & {$[0.092]$} & {$[0.757]$} & {$[0.392]$} & {$[0.470]$} & {$[0.085]$} \\
\hline$\overline{R^{2}}$ & 0.611 & 0.630 & 0.429 & 0.609 & 0.626 & 0.436 \\
\hline Adjusted $R^{2}$ & 0.466 & 0.492 & 0.223 & 0.462 & 0.485 & 0.233 \\
\hline SER & 0.075 & 0.073 & 0.101 & 0.075 & 0.074 & 0.100 \\
\hline $\mathrm{SC}$ & -1.635 & -1.682 & -1.058 & -1.629 & -1.669 & -1.071 \\
\hline
\end{tabular}

Notes: Asterisks $(* *)$ denote statistically significant at $5 \%$ level. Figures in round (...) brackets are $t$-statistics; and figures in square $[\ldots]$ brackets are $p$-values. All variables are in natural logarithm. SER and SC denote standard error of regression and Schwarz criterion, respectively.

\section{ACKNOWLEDGEMENT}

I would like to thank an anonymous referee for useful comments and suggestions. The usual disclaimer applies. Funding for this project comes from the Fundamental Research Grant Scheme (FRGS) Phase 1/2013 provided by the Malaysian of Higher Learning (MOHE). 


\section{REFERENCES}

Agnew, R. (2011). Dire forecast: A theoretical model of the impact of climate change on crime. Theoretical Criminology, 16(1), 21-42.

Anderson, C. A. (1989). Temperature and aggression: Ubiquitous effects of heat on occurrence of human violence. Psychological Bulletin, 106(1), 74-96.

Anderson, C. A. (2001). Heat and violence. Current Directions in Psychological Science, 10(1), 33-38.

Anderson, C. A. (2012). Climate change and violence. In D. J. Christie (Eds.), The Encyclopedia of Peace Psychology ( ${ }^{\text {st }}$ Ed.), London: Blackwell Publishing Ltd.

Anderson, C. A., \& Anderson, D. C. (1984). Ambient temperature and violent crime: Tests of the linear and curvilinear hypotheses. Journal of Personality and Social Psychology, 46(1), 91-97.

Anderson, C. A., Deuser, W. E., \& DeNeve, K. M. (1995). Hot temperatures, hostile affect, hostile cognition and arousal: Tests of a general model of affective aggression. Personality and Social Psychology Bulletin, 21(5), 434-448.

Banerjee, A., Dolado, J. J., \&Mestre, R. (1998). Error-correction Mechanisms Tests for Cointegration in a Single-equation Framework. Journal of Time Series Analysis, 19(3), 267-284.

Banerjee, A., Dolado, J. J., Galbraith, J., \& Hendry, D. F. (1993). Cointegration, Error Correction and the Econometric Analysis of Non-stationary Data. Oxford: Oxford University Press.

Baron, R. A. (1972). Aggression as a function of ambient temperature and prior anger arousal. Journal of Personality and Social Psychology, 21(2), 183-189.

Baron, R. A., \& Bell, P. A. (1976). Aggression and heat: The influence of ambient temperature, negative affect and a cooling drink on physical aggression. Journal of Personality and Social Psychology, 33(3), 245-255.

Bell, P. A., \& Baron, R. A. (1976). Aggression and heat: The mediating role of negative affect. Journal of Applied Social Psychology, 6(1), 18-30.

Britt, C. L. (1997). Reconsidering the unemployment and crime relationship: Variation by age group and historical period. Journal of Quantitative Criminology, 13(4), 405-428.

Butke, P., \& Sheridan, S. C. (2010). An analysis of the relationship between weather and aggressive crime in Cleveland, Ohio. Weather, Climate and Society, 2, 127-139.

Cohen, L. E., \& Felson, M. (1979). Social change and crime rate trends: A routine activity approach. American Sociological Review, 44(4), 588-608.

Cohn, E. G. (1990). Weather and crime. British Journal of Criminology, 1(30), 51-64.

Cohn, E. G., \& Rotton, J. (1997). Assault as a function of time and temperature: A moderator-variable time-series analysis. Journal of Personality and Social Psychology, 72(6), 1322-1334.

Cohn, E. G., \& Rotton, J. (2000). Weather, seasonal trends and property crimes in Minneapolis, 19871988. A moderator-variable time-series analysis of routine activities. Journal of Environmental Psychology, 20(3), 257-272.

Cotton, J. L. (1986). Ambient temperature and violent crime. Journal of Applied Social Psychology, 16(9), 786-801.

Dickey, D. A., \& Fuller, W. A. (1979). Distribution of the estimators for autoregressive time series with a unit root. Journal of the American Statistical Association, 74(366), 427-431.

Dickey, D. A., \& Fuller, W. A. (1981). Likelihood Ratio Statistics for Autoregressive Time Series with a Unit Root. Econometrica, 49(4), 1057-1077.

Gamble, J. L., \& Hess, J. J. (2012). Temperature and violent crime in Dallas, Texas: Relationships and implications of climate change. Western Journal of Emergency Medicine, 13(3), 239-246.

Horrocks, J., \& Menclova, A. K. (2011). The effects of weather on crime.New Zealand Economic Papers, 45(3), 231-254. 
MacKinnon, J. G. (1996). Numerical distribution functions for unit root and cointegration tests. Journal of Applied Econometrics, 11(6), 601-618.

McLean, I. (2007). Climatic effects on incidence of sexual assault. Journal of Forensic and Legal Medicine, 14(1), 16-19.

Ousey, G. C. (2000). Explaining regional and urban variation in crime: A review of research. Criminal Justice, 1, 261-308.

Ranson, M. (2014). Crime, weather and climate change. Journal of Environmental Economics and Management, 67(3), 274-302.

Rotton, J., \& Cohn, E. G. (2003). Global warming and U.S. crime rates: An application of routine activity theory. Environment and Behavior, 35(6), 802-825.

Salleh, S. A., Mansor, N. S., Yusoff, Z., \& Nasir, R. A. (2012). The crime ecology: Ambient temperature vs spatial setting of crime (burglary). Procedia - Social and Behavioral Sciences, 42, 212-222.

Sorg, E. T., \& Taylor, R. B. (2011). Community-level impacts of temperature on urban street robbery. Journal of Criminal Justice, 39(6), 463-470.

Tompson, L. A., \& Bowers, K. J. (2015). Testing time-sensitive influences of weather on street robbery. Crime Science, 4(8), 1-11.

Van de Vliert, E., Schwartz, S. H., Iiuismans, S. E., Hofstede, G., \& Daan, S. (1999). Temperature, cultural masculinity and domestic political violence: A cross-national study. Journal of CrossCultural Psychology, 30(3), 291-314.

Yasar, M., Nelson, C. H., \& Rejesus, R. M. (2006). The Dynamics of exports and productivity at the plant level: A panel data error correction model approach. In B. Baltagi (Eds.), Contribution to Economic Analysis. Amsterdam: Elsevier. 